\title{
Sub-optimal patient and physician communication in primary care consultations: its relation to severe and difficult asthma ${ }^{\text {th }}$
}

\author{
Mandy Moffat*, Jennifer Cleland, Thys van der Molen, David Price
}

Department of General Practice and Primary Care, University of Aberdeen, UK

Received 16 August 2005; accepted 22 February 2006

\begin{abstract}
KEYWORDS
Asthma;

Qualitative study;

Symptom control;

Patient experiences;

Professional-patient

communication

Summary

Introduction: Asthma control can be influenced by a range of lic n nacdical issues, including psychosocial factors. Little is "know wo the views of patients, particularly those with severe and cio r dif icult astnma, towards their asthma control and their asthmal re $a^{*} \in \mathrm{d}$ ? imary care consultations.

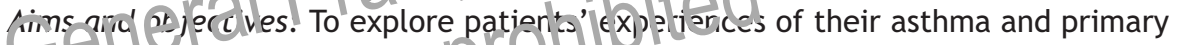
are asthma consultations in or/der to dentity target areas for intervention.

Methods: This v'als@ qualitative study of 14 asthma patients based in grounded the of. Questions were asked about: asthma understanding; control issues; and interactions with primary care health professionals. Data were analysed using the constant comparative method and framework approach.

Results: Participants with severe and/or difficult asthma normalised control issues, were reluctant to discuss non-medical factors with healthcare professionals (HCPs), reported poorer communication with HCPs, and were reluctant to raise relevant but non-medical factors in the consultation.

Conclusions: Our data identifies that patients, particularly those with severe and/or difficult asthma and poor control, underplay symptoms and do not discuss nonmedical factors which may impact on asthma control in primary care consultations. This poor communication is associated with patients underestimating disease severity and/or what could be achieved in terms of disease control. Training HCPs in the use of patient-centred communication skills may optimise asthma management in primary care.

( $) 2006$ General Practice Airways Group. Published by Elsevier Ltd. All rights reserved.
\end{abstract}

\footnotetext{
Within the article, quotes have been changed from Scottish vernacular to international English for ease of reading. Please contact the main author if you wish to see the data in its original form.

* Corresponding author. Department of General Practice and Primary Care, Foresterhill Health Centre, Westburn Road, University of Aberdeen AB25 2AY, UK. Tel.: +44 (0)1224 552485; fax: +44 (0)1224 550683.

E-mail address: m.moffat@abdn.ac.uk (M. Moffat).
} 


\section{Introduction}

Many asthma patients suffer from daily symptoms and activity restrictions even when prescribed maximally recommended doses of inhaled therapy $[1,2]$. Lack of control over symptoms can indicate severe or difficult asthma [3].

Asthma in the UK is now managed predominantly in primary care [4]: for example, nearly 4 million primary care asthma consultations occur each year [5]. Increased numbers of practice nurses (PNs) and the expansion of accredited asthma training for healthcare professionals other than doctors has led to much asthma care being delivered by nurses $[4,6]$. Thus, within primary care, patients with a range of asthma severity, including patients with difficult asthma and difficulties with control, are managed by general practitioners (GPs) and/or PNs.

A recent qualitative study identified that GPs and PNs find patients with psychosocial issues (e.g. patient lack of motivation and low expectations) and poor health behaviours (e.g. cigarette smoking, non-compliance with medication) difficult to treat effectively, particularly when these issues and behaviours are adversely affecting asthma management and control [7]. While earlier work has looked at the patient experience of asthma [8-10], little is known about the view's aid attitudes of those patients with difin-ilt and/or severe asthma towards cheir astruma consultations in primary care. (optivising asthma manage nent requires identification and $\mathrm{e} \times \mathrm{s}$. Pation of ine views and attitudes of patients towards both their asthma and their asthma-related interactions with GPs and PNs.

Therefore, the aims of this study were to explore patients' experiences of their asthma, and their primary care asthma consultations, in order to identify target areas for intervention.

\section{Method}

\section{Design}

This was a qualitative study using semi-structured interviews.

\section{Sample}

GPs who had taken part in another arm of the study were asked to identify and recruit eligible patients. Patients were eligible if they were 18 years of age or older, had a diagnosis of asthma for at least two years, were on Step 2 or above of the BTS/SIGN treatment guidelines [11], were not pregnant, did not have a diagnosis of COPD, and were thought by their GP to have severe and/or difficult asthma. Patients were also identified through a research database of volunteers, held by the Department of General Practice and Primary Care, University of Aberdeen, using the same eligibility criteria.

For the patients who agreed to participate, written, informed consent was obtained and interviews scheduled. Grampian Research Ethics Board approved this study.

Treatment step from the British Thoracic Society (BTS/SIGN) guidelines [11], plus control issues identified via the GP and through patient selfreport at interview, were used to stratify patients by severity and control.

\section{Procedure}

Patient interviews were carried out during $2002 / 2003$. These took place in patients' homes or a local health centre, whichever was more convenient for the patient. Interviews were semistructured in nature and lasted approximately 60 minutes. Confidentiality was als sured. The patients were asked about their uriderstanding of their asthin, their understanding of control is viles, and their experiences and views about recent primarj' Orel asthma consultations with their (iF andior PN. Attitudes towards healthcare professionals (e.g., relationships, perceived roles, what patients want from their practice nurse and GP) were explored [7].

Semi-structured interviews were used with an emphasis on open questioning and following up interesting aspects in relation to areas explored (an example can be seen in Figure 1). We stopped conducting interviews when saturation was reached and no new themes were emerging, in line with the grounded theory approach [12].

\section{Data management and analysis}

Interviews were taped, transcribed, and transcripts were checked for quality by the main researcher before being entered on $\mathrm{N}$-vivo [13]. $\mathrm{N}$-vivo was used to aid data management and coding. Excel was used to construct different frameworks for themes to be analysed more fully [14]. The interview data was analysed using a grounded theory approach, a form of qualitative research that can be useful for developing new theories or adding to existing theories [12].

Analysis was carried out by the main researcher $(M M)$ with discussion regarding emerging frameworks and coding strategies 
Background details -

Age? Occupation? Married? Children?

Interaction with General Practice-

Who do you see about your asthma?

How often do you see them?

Have you ever seen the PN (if GP)

History -

Can you remember when you were first diagnosed with asthma? What happened? What did your doctor

say to you? What kind of things were you told about your asthma?

How has your asthma changed over the years?

Have you seen the same healthcare professional?

How is your asthma just now?

Can you tell me about a period of time when your asthma was particularly bad?

What happened in the run up to your asthma getting worse? Can you explain it to me?

Did you see anyone about it? How did that go? What happened?

Can you tell when your asthma is about to get worse? Do you get any signs? Triggers?

Have you spoken to your GP/nurse about this?

Is there anything that affects your asthma that you feel you don't want to talk to your GP or practice nurse about? Why not?

Is there anything that affects your asthma that you do want to talk to your GP or nurse about but don't?

Medication use -

Nobody takes their medication $100 \%$ of the time. There are times for whatever reason, something just gets in the way.

Can you remember the last time you didn't use your inhaler or forgot and explain the circumetancesto me?

Did you tell the doctor/nurse? Were they able to help you

What do you do to remind yourself of wi atand vhen te takd your medication?

Personal tricks? How did yourome ac ross them?

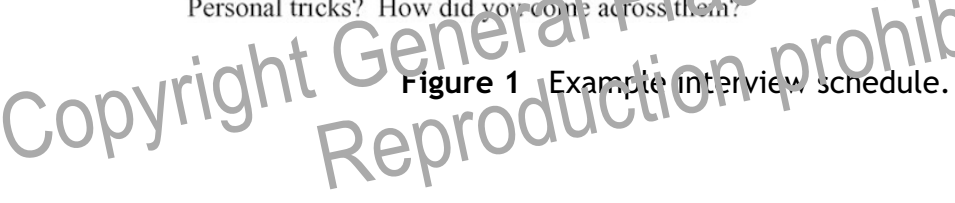

taking place at regular intervals (JC, TVM). Constant comparative analysis was used with emerging themes being identified and coded [12]. Descriptive themes were then reduced, synthesised and entered into different frameworks $[15,16]$. Cross-case comparisons between different participants and experiences were made (e.g. those with difficult/severe asthma and those with mild/controlled asthma). In addition, the original transcripts were revisited throughout the analysis to ensure that reduced and synthesised understandings were valid. Ongoing discussion between the authors enabled more specific coding, analysis, and understanding.

\section{Results}

Of the 23 patients who agreed to participate, 14 were enrolled in the study. Patients approached through the volunteer database gave lack of time and lack of interest in the study as the most common reasons for not participating. Further details regarding asthma symptoms or treatment, or personal details, were not obtained when patients did not wish to take part in the study. Six male patients and eight female patients were interviewed. Definitions of severe and/or difficult asthma were based on the broad definitions highlighted in an earlier study [3]. Eight interviewees were categorised as having severe and/or difficult asthma according to BTS treatment step and/or self-report and/or GP opinion.

Participants with severe asthma had all had previous contact with secondary care. At the time of the interview, only two patients, both of whom were on Step 5 of treatment [8], had ongoing contact with secondary care. Individuals with mildmoderate asthma tended to be managed solely in primary care.

Patients were predominantly working and middle class, and reflected the socio-economic profile of the area (Aberdeen, North-East Scotland). Most patients with difficult or severe asthma were unemployed or in low-income employment. 
Since our goal was to enhance understanding and generate hypotheses rather than achieve significance in a statistical sense, our findings are not presented numerically.

\section{Asthma control}

Factors believed by the patient to impact on asthma control were explored. The data indicated that perceptions of control and severity were couched in terms of relative experiences and in comparison to others.

For example, one participant explained that they did not see their asthma as being out of the ordinary ("I don't think I am such a rare case" Px35) although they did not know anyone else on daily oral steroids. Another participant, on BTS Step 4 medication, said "I get my good days and my bad days, but, because I've had it since I was 18 months I don't really know any other." (Px42). Even the patient who described himself as having "brittle asthma type 2"' (Px36), on high levels of daily antiasthma medication, still saw himself as a "free man' relative to other people with asthma. He explained that, on a day-to-day basis, his activities were not restricted compared to people he had witnessed during hospital stays (Table 1).

\section{Patient and professional views of inf uence:} on contros

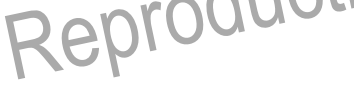

Most participants understood the triggers for their asthma exacerbations but some were reluctant to discuss all of these during the primary care consultation. For example, one participant stated that stress could exacerbate his asthma but explained that he wasn't "going to give him [the GP] all my troubles"' (Px37).

There was the view that primary healthcare professionals would assume triggers due to the patient's lifestyle without actually exploring this with the patient; in other words, the professionals had preconceived ideas of what might trigger an individual's asthma, but did not explore the patient's perspective.

Px 41: ...they always blame your weight.

Patients with severe/difficult asthma seemed less likely to discuss their personal situation or non-medical issues with primary healthcare professionals - even when these issues impacted on asthma control - than patients with controlled, mild-moderate asthma.

\section{Patient-professional relationships}

Patients with severe/difficult asthma described poorer relationships with professionals than those with controlled, mild-moderate asthma. In particular, they perceived GPs as being authoritarian, or paternalistic:

Px44: ... sometimes some doctors, because I'm asking for [an] extra inhaler, they can talk through things with me, and say "Why do you think you need another one?' ' and I just have to say "Well it's cause I'm smoking". They give you a row, give you an inhaler and then send you on your way.

Px49: Recently l've seen them [GPs] quite a bit...the last few months. Just cause l've had colds......... and they threatened me with the asthma clinic.

Px36: ... they (GPs) just wrap you up in cotton wool. It's just not what I want.

However, it was apparent that, when control issues do occur, the professional-patient relationship is critical:

Px35: If I have a bad attack thent first point of call is 'Py CPE I: DrXXX (hospital consultant) Sas given me a letter saying if I feel that I am not handling my symptoms myself I can ap nit myself to Ward 2 but usually $I$ go to my GP first and they decide.

Thus, it seemed that the ability to access, communicate and gain the information and attention needed to regain asthma control was important to patients. Accessing help when required was important to all participants but, as would be expected, more so by participants with poor control.

\section{Communication within the consultation}

The interview data indicated that participants with difficult/severe asthma voiced negative attitudes towards professionals. The data suggested that these negative attitudes were associated with poor communication within the consultation. For example:

Px35: ... he says "Right, what's been going on, how's your asthma'? and he is just wanting you out of there, he just wants on to the next one.

Communication issues were particularly apparent in patients with severe/difficult asthma for example, in terms of discussing compliance with prescribed medication. Only three participants 
Table 1 Details of participants

\begin{tabular}{|c|c|c|c|c|c|c|c|}
\hline Participant & Age group & Asthma onset & $\begin{array}{l}\text { BTS treatment } \\
\text { step }\end{array}$ & $\begin{array}{l}\text { Hospital } \\
\text { admissions }\end{array}$ & $\begin{array}{l}A \& E \\
\text { visits }\end{array}$ & $\begin{array}{l}\text { Main } \\
\text { contact }\end{array}$ & $\begin{array}{l}\text { Asthma: Severe } \\
\text { (S) Difficult (D) } \\
\text { Controlled (C) }\end{array}$ \\
\hline$P \times 35$ & $20-29$ & Early childhood & $5^{a}$ & Yes & Yes & Consultant & S, D \\
\hline$P \times 36^{b}$ & $20-29$ & 2 years ago & $5^{b}$ & Yes & Yes & All & S, D \\
\hline P×37 & $30-39$ & Early childhood & $3-4$ & Yes & Yes & GP & S, D \\
\hline Px39 & $30-39$ & Since 15 & $3^{a}$ & No & No & GP & D \\
\hline$P \times 44^{b}$ & $20-29$ & Early childhood & $3^{a}$ & No & No & GP & $\mathrm{D}$ \\
\hline Px49 & $20-29$ & Since $5 / 6$ & 3 & No & Yes & GP & D \\
\hline $\mathrm{P} \times 38^{\mathrm{b}}$ & $50-59$ & Diagnosed 30's & 2 & No & Yes & PN & D \\
\hline Px42 & $40-49$ & Early childhood & 4 & Yes & No & GP & $C, \mathrm{~S}$ \\
\hline$P \times 41$ & $40-49$ & $9-10$ years ago & 3 & No & No & GP & $\mathrm{C}$ \\
\hline$P \times 43$ & $50-59$ & 6 years ago & 2 & No & No & PN & $\mathrm{C}$ \\
\hline$P \times 45$ & $30-39$ & Early childhood & 2 & No & No & None & C \\
\hline Px46 & $60-69$ & 10 years ago & 3 & No & No & GP & C \\
\hline$P \times 47$ & $50-59$ & $1 \frac{1}{2}$ years ago & 2 & No & No & GP & $\mathrm{C}$ \\
\hline Px48 & $20-29$ & 1 year ago & 2 & No & No & PN & $\mathrm{C}$ \\
\hline
\end{tabular}

a Taking considerably less medication than prescribed.

b Smokes.

with difficult/severe asthma described taking their medication as prescribed. Most other participants with severe/difficult asthma took significantly less medication (i.e. beyond occasionally forgetting) than prescribed. Not taking medication, and the reasons for this, were not raised by patients within the consultation. For example, one patient acknowledged that they had recently cold their GP that they did not thin $\epsilon$ the inedication as prescribe but only when this discussion vas initiated $b y$ tine GP and they we as fied a direct question about compliance. Similarly, two other participants stated that they would only admit to not taking their inhaled steroid if asked directly by their GP. Note, however, that not taking medication as prescribed was not restricted to those with difficult asthma.

Thus, patients are aware that they are not following treatment as recommended by their practice nurse or GP but they will not volunteer this information in the consultation. This reluctance could be due to anxiety that the healthcare professional would react negatively.

\section{Topics seen as suitable for the consultation}

Participants with milder/more controlled asthma tended to feel that they received the time they required from primary care staff. However, the data indicated that patients with more severe or difficult asthma viewed some topics as unsuitable for discussion within the consultation. The range of topics was quite narrow and medically-focused even when the patient knew that broader (i.e., non-medical) issues were affecting their asthma symptoms or triggering asthma exacerbations. For example:

MM: When jour ientio:lea things like at work, is th Stress that sometimes brings it on?

2.37: Stress ave

$M M: P \rho y \|$ feet us if you can talk to your GP about that?

PX37: No I don't mention anything like that.

MM: Why not?

PX37: I don't know. It's just that ... If I need help to get it cleared up I just go up and I try to see about it. I'm not going to give him all my troubles.

MM: So do you just sort of tell them then that your asthma's getting bad but you don't...

PX37: I just phone them up and say "Look I need a bit of help, my asthma's getting bad"' and he just says "Come right up". So......

MM: You don't really talk to him about stress at work or anything like that.

PX37: No, no.....

MM: I mean does he know that stress is one of the triggers at all or is it something that's not discussed.

PX37: I don't think he knows, I'm not sure. It's never been discussed.

This illustrates the interplay between several separate, but interconnecting, issues. Patients do not discuss non-medical matters in the consultation and perceive that they should cope with these broader, non-medical issues themselves. 
There was also data to support the notion that patients' perceptions of the time limits of primary care consultations, particularly GP consultations, influence patient behaviour in the consultation:

Px42: "the doctors are busy enough!"

Px38: "What is it, a five minute interview with the doctor?... (with the practice nurse) you've got time to mention anything that's cropped up'”

\section{Discussion}

Although there has been work looking at the experiences of patients with asthma [8-10], this is the first data reported on views of people with 'difficult' and/or severe asthma towards management of their asthma by primary healthcare professionals. This is interesting in the light of Bellamy and Harris's recent paper, and the accompanying editorial, in a recent issue of the Primary Care Respiratory Journal $[17,18]$. Their study identified that patients, particularly those with severe/difficult asthma and poor control, report poor communication within the consultation and do not feel comfortable raising lifestyle, or non-medical factors, for discussion within the consultation even where they areandeit that these impact on their $d s t / m$. Toeldaia suggested that this was as:ocig ted with asthma paltients underestirnating the severivorthe ir cisease and under-treating symptoms.

This paper presents a small, qualitative study carried out in one geographical area of the UK so the findings may not be generalizable. However, care was taken when arranging the interviews to ensure that a wide spectrum of patient views and experiences were represented: qualitative research does not aim to produce findings that are representative of larger populations in the same way as more traditional quantitative research aims to do [19]. Participants with control issues at the time of interview tended to be from lower socio-economic groups. Comparisons were made with the experience of one participant (professional) who had control issues, who reported that communication with their HCP was not ideal but that both parties had worked to overcome this issue. It may be useful in a future study to explore patient experiences in relation to HCPs' different consultative styles (as previously noted by Lagerlöv and colleagues [20]) since different consultative styles may be preferred by different patients.

Educating asthmatic patients to recognize accurately and to respond to their own symptoms is critical: poor perception of symptoms, leading to under treatment of symptoms, has been associated with near-fatal asthma [21], as well as impacting on patient quality of life [22]. Paradoxically, in our data poor perception of symptoms was accompanied by the acknowledgement that psychological factors, such as stress, impacted on control through a number of possible routes [23-26]. We know that patients with control issues do not know they could be better $[2,8,27]$ : this data suggests that patients may acknowledge lifestyle triggers but may assume that nothing can be done to improve their symptom management, so why report these factors in the consultation? In other words, acceptance of sub-optimal control has consequences for patient help-seeking behaviour. Jones et al's study of COPD patients indicated that when patients are unsure as to what symptoms indicate poor control, or an exacerbation, they are reluctant to "bother the doctor." [28] The data from the present study found a similar pattern of behaviour in asthma patients. Opportunities within the consultation for the GP to work with the patient to optimise asthma management may be livliefd due to patients not recognizing simpioms or taking their own Nefisiors as to what information is, Q1. is riot, relevant for discussion within the consultation

Prinary healthcare professionals may not wish to explore patient symptoms and level of control in more depth due to class-based barriers to communication [29], lack of skill and/or confidence, and/or the (possible mis-) perception that patients are not open to this discussion. We suggest that the onus is on the professional to use patient-centred communication skills [30] to gather appropriate information from the patient on a range of disease and illness characteristics [31]. Patients may also be more open to discussing their symptoms and relevant lifestyle factors within the consultation when made aware of what can indeed be achieved in terms of asthma control, particularly when advice about achieving better control is personalised and tailored to their individual needs [32].

Training professionals in patient-centred asthma management [33] to develop the communication skills required to help a range of patients with individual disease characteristics, personal attributes and lifestyles, may be an important factor in asthma practice, as well as optimising asthma treatment and management, particularly in poorly controlled asthma patients. This may lead to greater satisfaction for both healthcare professionals [34] and patients. 


\section{References}

[1] Price D, Ryan D, Pearce L, Bride F. The AIR Study: asthma in real life. Asthma J 1999;4:74-8.

[2] Haughney J, Barnes G, Partridge MR, Cleland J, The Living. \& Breathing Study: a study of patients' views of asthma and its treatment. Prim Care Resp J 2004;13:28-35.

[3] Moffat M, Cleland J, van der Molen T, Price D. Definitions of severe and difficult asthma by a group of UK general practitioners. Prim Care Resp J 2002;11(3):99-102.

[4] Levy M, Hilton S. Asthma in Practice. The Royal College of General Practitioners; 1999.

[5] Masoli M, Fabian D, Holt S, Beasley R. Global Burden of Asthma. GINA, 2004 Report.

[6] Dawson S, Sutherland K, Dopson S, Miller R. Changing clinical practice: views about the management of adult asthma. Qual Health Care 1999;8:253-61.

[7] Moffat $M$. The management of severe and difficult asthma in general practice: A qualitative study [dissertation]. 2005.

[8] Hewett G. Just a part of me - Men's reflections on chronic asthma. London: South Bank University; 1994. Report No. 1.

[9] Mancuso CA, Rincon M, Robbins L, Charlson ME. Patients' expectations of asthma treatment. J Asthma 2003;40(8):873-81.

[10] Scherman MH, Dahlgren LO, Lowhagen O. Refusing to be ill: a longitudinal study of patients' experiences of asthma/allergy. Disabil Rehabil 2002;24(6):297-307.

[11] Scottish Intercollegiate Guidelines Network, The British Thoracic Society. British guideline on the management of asthma. Thorax 2003;58(Suppl I):i1-i94.

[12] Strauss A, Corbin J. Basic of Qualitative Research: Grouncea Theory Procedures and Techniques. London: $S_{2} g=; 778$.

[13] QSR International Pty Ltd. Q.SR. N-y 1. P ton Nicrosoft Windows 2000

[14] Microsc ft C orporation. Mic osoft Excel 2000

[15] Miles $M 2$, huberman $A M$. Qual t-ci $\bullet$ data unalysis: An expanded sourcebook. London: Suge; 1994.

[16] The Qualitative Research Unit,National Centre for Social Research. The conduct of qualitative depth interviews 2002.

[17] Bellamy D, Harris T. Poor perceptions and expectations of asthma control: Results of the International Control of Asthma Symtpoms (ICAS) survey of patients and general practitioners. Prim Care Resp J 2005;14(5):252-8.

[18] Cleland J, Price D. Achieving optimal asthma control: Can this be informed by recent studies of professional-patient communication? Prim Care Resp J 2005;14(5):233-5.
[19] Mays N, Pope C. Assessing quality in qualitative research. BMJ 2000;320:50-2.

[20] Lagerlov P, Leseth A, Matheson I. The Doctor-Patient Relationship and the Management of Asthma. Soc Sci Med 1998;47(1):85-91.

[21] Dhuper S, Maggiore D, Chung V, Shim C. Profile of near-fatal asthma in an inner-city hospital. Chest 2003;124:1880-4.

[22] Ehrs P, Larsson K. Treatment improves quality of life in patients with poor perception of asthma. Prim Care Resp J 2004;13:42-7.

[23] Smyth JM, Soefer MH, Hurewitz A, Kliment A, Stone AA. Daily psychosocial factors predict levels and diurnal cycles of asthma symptomatology and peak flow. J Behav Med 1999;22(2):179-93.

[24] Goodwin RD. Asthma and anxiety disorders. Adv Psychosom Med 2003;24:51-71.

[25] Bosley CM, Fosbury JA, Cochrane GM. The psychological factors associated with poor compliance with treatment in asthma. Eur Resp J 1995;8:899-904.

[26] Nagata S, Irie M, Mishima N. Stress and asthma. Allergol Int 1999;48:231-8.

[27] Sawyer SM, Fardy HJ. Bridging the gap between doctors' and patients' expectations of asthma management. J Asthma 2003;40(2):131-8.

[28] Jones RCM, Hyland ME, Hanney K, Erwin J. A qualitative study of compliance with medication and lifestyle modification in Chronic Obstructive Pulmonary Disease (COPD). Prim Care Resp J 2004;13:149-54.

[29] Willems S, De Maesschalck S, Deveugele M, Derese A, De Maeseneer J. Socio-economic scatur of he patient and doctor-patient commınicalion: c'oes it make a difference? Patient Educ Coun : Oot; ;6:139-46.

[30] Naguie P, Pitceathly C. Key communication skills and how to acquire them. RN: 20,2;325(7366):697-700.

[31] Lewin st, skea 7-, Eniwistle V, Zwarenstein M, Dick J. Int -vertions for providers to promote a patient-centred a,proach in clinical consultation. The Cochrance Database of Systematic Reviews [serial online] 2001 (4):27/07/05.

[32] Butler C, Pill R, Stott NCH. Qualitative study of patients' perceptions of doctors' advice to quit smoking: implications for opportunistic health promotion. BMJ 1998;316:1878-81.

[33] Clark NM, Gong M. Management of chronic disease by practitioners and patients: are we teaching the wrong things? BMJ 2000;320:572-5.

[34] Edwards A, Elwyn G, Wood F, Atwell C, Prior L, Houston $H$. Shared decision-making and risk communication in practice: a qualitative study of GPs' experiences. B J Gen Pract 2005;55(510):6-13.

\section{Available online at www.sciencedirect.com science@Direct.}

